\title{
Estigma e discriminação: desafios da pesquisa e das políticas públicas na área da saúde
}

MONTEIRO, Simone; VILLELA, Wilza.

Estigma e Saúde.

Rio de Janeiro: Fiocruz, 2013. 207 p.

\section{| ${ }^{1}$ Ivia Maksud I}

${ }^{1}$ Cientista Social pelo IFCS-UFRJ, doutora em Saúde Coletiva pelo IMS-UERJ e professora adjunta da Universidade Federal Fluminense. Niterói, Brasil. Endereço eletrônico: iviamaksud@id.uff.br

Esta coletânea, lançada em 2013 pela Editora Fiocruz, apresenta textos resultantes do encontro "Estigma e Discriminação: desafios da pesquisa e das políticas públicas”, realizado em 2 de junho de 2011 no Rio de Janeiro e organizado pelas pesquisadoras Simone Monteiro (Fiocruz) e Wilza Villela (UNIFESP e UNIFRAN), profissionais de longa e reconhecida trajetória nos estudos brasileiros sobre HIV/Aids.

A publicação visa, nas palavras das organizadoras, "apresentar alguns dos desafios teóricos, epistemológicos e políticos presentes na produção do conhecimento sobre estigma e discriminação no campo da saúde" e "fornecer aportes conceituais e metodológicos capazes de orientar pesquisas e políticas na área voltadas para o enfrentamento dos processos de estigmatização entre diferentes grupos e contextos sociais e suas repercussões sobre a saúde” (p. 13).

O tema "estigma, discriminação e saúde" é minuciosamente discutido em 11 textos produzidos por renomados pesquisadores nacionais e internacionais, inseridos em diferentes contextos de pesquisa.

A coletânea guarda a estrutura dos debates realizados no referido encontro. $\mathrm{Na}$ ocasião, os autores estavam situados como apresentadores e debatedores, por vezes aproximando-se teoricamente, por vezes complementando-se a partir de distintas óticas teóricas ou disciplinares. Tal fato torna o conjunto de textos 
deveras atraente, nos proporcionando uma leitura instigante e entusiasmada, animada pelo tratamento dialógico conferido aos textos por seus autores.

Como anteriormente bem observado por José Ricardo Ayres e Vera Paiva (que escrevem prefácio e orelha da obra, respectivamente), a coletânea nos coloca diante de diferentes abordagens e possibilidades de pensar estigma, discriminação e saúde - multiplicidade característica do próprio campo da Saúde Coletiva no Brasil. O resultado final que se tem em mãos é uma obra rica e plural, capaz de ofertar ao público leitor - acredito, também plural - um cardápio interessante e variado de enfoques epistemológicos e disciplinares.

A apresentação das organizadoras já anuncia e enfrenta os desafios teóricos, epistemológicos e políticos da pesquisa sobre estigma e discriminação no campo da saúde no Brasil, mostrando-nos, por exemplo, através de resultados de recente revisão de literatura, que no Brasil "as pesquisas acerca das consequências do estigma e da discriminação nos agravos à saúde são escassas” (p. 15).

A coletânea é aberta com o artigo do antropólogo Richard Parker, referência obrigatória nos estudos sobre HIV/Aids. Parker, que há muito se debruça sobre o tema "estigma e discriminação", ${ }^{1}$ elege três conjuntos de questôes principais em seu texto: 1) analisa a literatura recente (em especial a norte-americana, mas não só) sobre estigma e preconceito e sua relação com a discriminação; 2) propõe repensar o estigma, o preconceito e a discriminação como processos sociais ligados à estrutura de poder e dominação; e 3) examina como estigma, preconceito e discriminação, bem como as desigualdades sociais e a violência estrutural têm sido associados ao que vê como as duas principais tendências atuais da saúde pública/coletiva: saúde e direitos humanos e saúde e justiça social.

Parker identifica como os primeiros grandes esforços acadêmicos a publicação dos livros de Gordon Allport (A Natureza do Preconceito, de 1954) e de Erving Goffman (Estigma, de 1963). (Parte dos autores da coletânea voltará a fazer menção a essas obras, em maior ou menor grau). Parker nos mostra que, ao longo dos anos, a produção de conhecimento relacionada a preconceito e discriminação esteve ligada a questões ligadas ao racismo, ao passo que a maior parte das pesquisas sobre estigma se deu em relação a várias doenças e, a partir da década de 80, incrementou-se com a epidemia de HIV/Aids. Segundo análise do autor, tanto as pesquisas sobre "preconceito" quanto as pesquisas sobre "estigma" têm sido realizadas a partir de diferentes perspectivas disciplinares nas ciências 
sociais e na psicologia. Ao que parece, "discriminação" não teria o mesmo valor conceitual, ao passo que tem sido usada menos como recurso teórico e mais como recurso de ação. (Esses limites e imprecisões entre os usos de um ou outro conceito serão daí em diante abordados/problematizados por vários autores da coletânea, o que parece constituir, de fato, uma das questões centrais do livro).

Nesse artigo, Parker retoma uma ideia anterior na qual formula uma crítica ao conceito goffminiano de estigma, a partir das repercussões do estigma para o HIV/Aids: "ir além da formulação teórica inicial de Erving Goffman segundo a qual o estigma é uma espécie de marca, uma diferença de valor negativa e, em vez disso, pensar sobre o estigma como uma espécie de processo social, fundamentalmente ligado ao poder e à dominação" e [compreendê-lo] "mais claramente como ligado ao funcionamento das 'desigualdades sociais"' (p. 29). Para o autor, as pesquisas mais recentes sobre estigma, preconceito e discriminação que se destinam a pensar cada um desses temas de forma mais ampla - ou seja, considerando os processos culturais, as estruturas de poder e as possibilidades de resistência - "nos conduzem a uma compreensão mais fundamentalmente social e política desses processos” (p. 31). Deriva daí a importância de relacioná-las com o conceito de "violência estrutural", central em seus escritos. ${ }^{2}$

O segundo artigo da coletânea é de autoria do antropólogo Octavio Bonet, que debate o texto de Parker. Para ele, o autor estrutura sua argumentação em dois níveis: um primeiro, que se destina à investigação da construção conceitual de estigma, preconceito e discriminação e a reformulação desses como processos sociais, e um segundo nível, preocupado com as ações programáticas que podem derivar da teoria. $\mathrm{O}$ texto de Parker instiga novas reflexões de Bonet acerca de suas próprias pesquisas realizadas no contexto da atenção básica, em especial no Programa de Saúde da Família. A um só tempo, Bonet traz à baila o conceito de violência simbólica de Pierre Bourdieu para conversar com o conceito de violência estrutural proposto por Parker e realizar uma releitura de seus achados empíricos. Analisando um lócus específico envolto por estigma e discriminação, Bonet pergunta:

[...] como lidar com o paradoxo que se apresenta em relação a esses dois modos de violência, estrutural e simbólica, nas politicas e programas de APS como a ESF, que ao mesmo tempo que ajudam a diminuir as desigualdades de acesso a saúde, e portanto a violência estrutural - evitando que se produzam mortes evitáveis, por exemplo -, instauram uma violência simbólica que se manifesta nos relacionamentos cotidianos entre os profissionais da saúde e as populações alvo das políticas e dos programas? (p. 50). 
Ainda em diálogo com as propostas presentes no texto de Parker, Bonet chama atenção para a distância entre as intenções das políticas de saúde e as realidades sobre as quais elas se dirigem, mostrando os processos de discriminação que são dados ao longo das metaforizaçōes produzidas pelos diversos atores sociais. Outro ponto alto do artigo de Octavio Bonet é sua menção, no contexto acadêmico brasileiro, a um importante e pioneiro trabalho sócio-antropológico sobre estigma e preconceito: trata-se de Vozes de Campos do Jordão, de Oracy Nogueira. A obra, que ganhou edição revista por Maria Laura Viveiros de Castro Cavalcanti e publicada pela Fiocruz em 2009, é um dos clássicos das Ciências Sociais brasileiras que muito tem a contribuir com os estudos de Saúde Coletiva. ${ }^{3}$

O terceiro artigo da coletânea é uma revisão bibliográfica comentada de autoria de Simone Monteiro, Wilza Villela, Carla Pereira e Priscilla Soares. Para as autoras, a produção brasileira recente sobre estigma, discriminação e saúde no Brasil é pouco expressiva, embora regular, com predomínio na área de saúde coletiva e saúde mental, e dos seguintes temas: cor/raça e DST/Aids. Os artigos relativos ao objeto raça/cor usam predominantemente os termos "discriminação" ou "preconceito", referindo-se à exclusão social. Os artigos relativos aos agravos de saúde tendem a utilizar o termo "estigma", "considerando sua origem na marca corporal, a doença, e tomando como objeto os processos de discriminação que se articulam em torno dos portadores de doença, especificamente estudada como consequência das representaçōes culturais sobre a doença" (p. 66). As autoras informam também que há um predomínio das estratégias qualitativas na produção de literatura sobre o tema, e, no caso mais específico dos artigos sobre HIV/Aids, as autoras sinalizam carência de análises teóricas.

As revistas em que se publicam tais artigos são de saúde coletiva, psicologia e enfermagem, nessa ordem, apontando uma tendência de estudar o estigma com base nas experiências individuais mais do que como processo - ou, nas palavras das autoras, "em detrimento de estudos que busquem compreender a dinâmica de produção do estigma relacionado ao HIV/Aids em relação aos demais vetores de desigualdade social que têm orientada a disseminação da epidemia” (p. 69), em que as autoras concordam com o texto de Richard Parker.

As autoras assinalam a sobreposição das bases conceituais de estigma e vulnerabilidade nesta literatura (observação que pode ser vista em outros artigos da coletânea): 
[...] a importância de incorporação do conceito de vulnerabilidade nos estudos sobre

Aids e a ideia de que o estigma é um dos vetores da construção da vulnerabilidade ao HIV/AIDS podem ter colaborado para que a abordagem do estigma tenha sido referida mediante sua compreensão como um componente da vulnerabilidade, numa espécie de subsunção de uma ideia a outra (p. 75).

Daniela Knauth, que dialoga com as autoras e escreve o quarto artigo da coletânea, faz uma instigante reflexão, a meu ver, sobre a escassez de estudos sobre estigma no campo acadêmico, e chama atenção que "poucos trabalhos se debruçam sobre os processos sociais geradores e reprodutores de estigma e disciminação" (p. 82). Segundo ela, "estigma é percebido basicamente como consequência de uma doença ou de uma situação que, por sua vez, é objeto de discriminação social!” (p. 82). Para Knauth, "a perspectiva do sofrimento se apresenta como um ponto-chave da concepção de estigma e discriminação" na literatura examinada (p. 84), perspectiva esta que se articula bem com o conceito goffminiano que "tem por eixo o sujeito, seu corpo e sua experiência" (p. 85). O tema, na opinião da autora, é ele mesmo objeto de interesse de áreas que na hierarquia do campo médico são discriminadas ou estigmatizadas. Talvez, ela conclui, esse seja um tema com mais repercussão fora da academia - assunto por excelência mais político do que acadêmico. Por fim, Knauth destaca que "outro elemento que poderia estar contribuindo para a discussão da exiguidade de estudos sobre Aids e discriminação é um certo envelhecimento do tema” (p. 87), que poderia estar relacionado também a um peso menor que teriam as ciências sociais e humanas nos estudos sobre Aids.

Francisco Inacio Bastos ocupa-se do quinto artigo da coletânea. Num texto científico e poético, o autor trabalha com a ideia da persistência de metáforas relativas ao estigma e a discriminação do HIV/Aids. Ele chama atenção que "do ponto de vista epidemiológico, não faz mais sentido falar na disseminação do HIV/Aids como um fenômeno propriamente epidêmico em termos globais" ( $\mathrm{p}$. 94), dada a diversidade mundial e de próprias epidemias em cada região ou país, ou mesmo questôes geracionais. É ainda notável a forte associação da doença com o imaginário social que foi produzido sobre ela em meados das décadas de 80 e 90 . Segundo o autor:

[...] as pessoas que vivem com Aids hoje são, em termos globais, tão diversas como são diversas quaisquer outras populaçôes em um mundo profundamente heterogêneo e injusto. Por um lado, tal constatação pode levar a um desdobramento favorável, qual seja, a impossibilidade de dar concretude física ao estigma, o que estaria em oposição 
à sua conotação original de marca física (ou stigmatta, no termo original grego), presente tanto na tradição greco-romana quanto na judaico-cristã. Por outro lado, uma suposta "ameaça sem rosto" é algo profundamente assustador no imaginário social, como na película recentemente lançada por Pedro Almodóvar sobre um ser sem rosto próprio, em La Piel que Habito (2011). (p. 97)

Por fim, Bastos faz uma observação sociológica afirmando que, no mundo social, o estigma se repete, se atualiza e se reinventa, demonstrando a persistência de diferenciações e hierarquias nas sociedades.

Ivan França Jr. e Eliana Miura Zuchchi são responsáveis pelo sexto texto da publicação e escolhem abordar as fragilidades teórico-metodológicas na produção acadêmica brasileira sobre estigma em Aids. Dialogando com a provocação feita por Bastos acerca de uma "persistência de metáforas estigmatizantes acerca da Aids" (p. 105), os autores clamam para a "necessidade de uma reflexão mais aprofundada acerca do estigma e suas condições de (re) produção” (p. 105) e, assim, buscam "caracterizar a literatura científica brasileira sobre estigma em Aids publicada no Brasil, analisar a intencionalidade do uso do termo "estigma" e avaliar os sentidos com que o conceito é empregado” (p. 107).

Em sua empreitada, observam diferentes intenções de uso do conceito nos artigos analisados, classificando-os a partir de duas possibilidades de emprego: "um primeiro emprego [...] de apreensão parcial do conceito, caracterizando o estigma descritivamente, como atributo individual ou do grupo de portadores, estático [...], e o outo emprego denota o uso analítico-interpretativo de estigmatização como processo social” (p. 108). Realizam um exercício analítico de releitura de variadas pesquisas mostrando-nos que o termo "estigma" é nelas utilizado sem devido aprofundamento. Concluem os autores que "são poucas as pesquisas em Aids no campo da saúde coletiva que incorporam, em termos teóricometodológicos, plenamente o conceito de estigma em seus empreendimentos intelectuais" (p. 113).

O sétimo capítulo do livro é de autoria de João Luiz Bastos e Eduardo Faerstein, que analisam os aspectos conceituais e metodológicos das relações entre discriminação e saúde em estudos epidemiológicos. (Convém notar que os autores não trabalham com o termo "estigma”, mas sim com "discriminação", "preconceito" e "estereótipo"). Partindo de definições conceituais de discriminação mais ligadas à psicologia social, apresentam "o estado da arte dos estudos sobre as relações entre discriminação interpessoal e condições de saúde" 
e realizam uma revisão sistemática da literatura, discutindo "instrumentos

disponíveis para medir a discriminação e apresenta-se uma proposta para sua aferição em estudos epidemiológicos brasileiros” (p. 116). Os autores também apontam imprecisões e falta de rigor metodológico na literatura que aborda relações entre discriminação e condições de saúde, podendo ser encontrados com facilidade “trabalhos que empregam os termos 'preconceito' e 'discriminação' de maneira intercambiável, quando o fenômeno avaliado se refere exclusivamente à discriminação" (p. 117). E os autores mostram que "é a discriminação que tem sido mais frequentemente operacionalizada nos estudos epidemiológicos, ainda que com importantes limitações” (p. 119). Passam então a discorrer sobre discriminação e condições em saúde, chamando atenção para variados objetos, como condições e comportamentos em saúde da população negra, tabagismo, uso e abuso de álcool, saúde mental, orientação sexual e condições adversas de saúde (p. 119). As condições de saúde mais frequentemente avaliadas em relação à discriminação dizem respeito à saúde mental, seguidas por pressão arterial, e estado geral de saúde (onde se encaixam estudos dos mais diversos - cabe refletir se aqui já não haveria uma classificação prévia na definição do objeto: comportamento saudável, por um lado, e abuso de drogas, por outro). Ao final do artigo, os autores propóem um instrumento que tem, em suas palavras “desempenho satisfatório na avaliação de experiências discriminatórias" (p. 130).

No oitavo capítulo da coletânea, Kenneth Rochel Camargo Jr. complementa a discussão realizada por Bastos e Faerstein, acendendo o diálogo entre a epidemiologia e as ciências sociais e humanas. Situando sua fala no campo dos estudos da ciência, o autor reflete sobre o campo, fazer científico e diferenças entre as ciências naturais e as ciências humanas, trazendo para a discussão autores que teorizam sobre o campo da ciência: Thomas Kuhn, "que propôs a categoria analítica de paradigma para a descrição do fazer científico” (p. 135), Charles Taylor, para quem, segundo Camargo Jr., "as ciências humanas são basicamente hermenêuticas e, devido a essa característica, em seu âmbito não há uma interpretação final, última, definitiva, a ser alcançada” (p. 136), e Knorr-Cetina, que

[...] chama a atenção para o fato de que as interações no domínio da ciência não se esgotam no diálogo entre os cientistas, nem estes atuam simplesmente em função de questôes internas à pesquisa; o que se poderia denominar "político" e "científico" se entrecruza em arenas que incluem cientistas, gerentes de agências financiadoras, representantes da sociedade civil e assim por diante (p. 137). 
O autor também debate sobre questões internas ao próprio campo da epidemiologia, chamando atenção para contribuições de importantes autores situados no chamado campo da epidemiologia social que questionam, por exemplo, limitações dos modelos epidemiológicos que não considerem o contexto, como Mervin Susser, George Kaplan e Nancy Krieger. Para o autor:

[...] estudar a discriminação como potencial agravo à saúde é um objetivo social e cientificamente válido. Para que se possa alcançá-lo, contudo, é preciso considerar alguns requisitos: a necessidade de trabalho efetivamente interdisciplinar ao longo de todo o processo, desde o desenho inicial até a análise dos resultados; a incorporação teórica rigorosa da tradição de pesquisa social adotada; a participação, sempre que possível, de indivíduos afetados pelo tipo de discriminação que se deseja estudar, mas que também possam dialogar de modo próximo com os pesquisadores (idealmente, que sejam eles próprios parte das equipes de pesquisa); a constante vigilância contra a reificação de categorias adotadas para estudo, que tenderia a reforçar precisamente aquilo que se deseja evitar; a adoção de múltiplas técnicas de pesquisa, adequadas aos diversos níveis de abrangência dos fenômenos estudados. E, fundamentalmente, é preciso assumir de antemão que tanto a discriminação quanto o processo saúde-doença são objetos complexos, que demandam abordagens igualmente complexas [...] há a necessidade de fortalecer o rigor interdisciplinar, mantendo, contudo, o rigor conceitual necessário (p. 141).

Os capítulos nono e décimo apresentam pesquisas etnográficas a partir do tema "estigma, discriminação e saúde". Sergio Carrara aborda o tema da discriminação a partir das políticas e direitos sexuais no Brasil. Tomando como referências para pensar o conceito de política sexual de Jeffrey Weeks e o dispositivo da sexualidade de Michel Foucault, Carrara reflete sobre o ideário dos direitos humanos e a política sexual brasileira. Nas palavras do autor, "homens e mulheres que rompem com convenções sociais de gênero e sexualidade estão particularmente expostos a situações de violência e discriminação”. (p. 145). Num primeiro plano, o autor analisa vários exemplos de casos de violência que são classificados como "violência homofóbica" que, segundo ele, "se reveste das características mais clássicas dos chamados crimes de ódio” (p. 147). O autor faz também uma análise da agenda LGBT, mostrando que "além de reivindicar a proteção do Estado contra a violência homofóbica em sua forma mais brutal (agressões verbais, físicas e assassinatos)" há demandas como "direito ao reconhecimento legal de relações afetivo-sexuais, à adoção conjunta de crianças, à livre expressão de sua orientação sexual e/ou de gênero em espaços públicos, à redesignação do 'sexo' e à mudança do nome em documentos de identidade, 
ao acesso a politicas de saúde específicas" (p. 148). O autor analisa também a

política sexual contemporânea no plano estatal, observando, por um lado, a Constituição Federal de 1988 - dentre outras coisas, "marco fundamental a partir do qual a sexualidade e a reprodução se instituíram como campo legítimo de exercícios de direitos no Brasil” (p. 152), e olhando também as políticas públicas LGBT que vêm sendo desenhadas pelo Governo Federal, no âmbito de vários Ministérios e Secretarias.

Luciane Ouriques Ferreira reflete sobre as relações entre estigma e vulnerabilidade em saúde a partir da prática do "esperar troquinho", realizada por mulheres e crianças mbyá-guarani no Centro de Porto Alegre. A autora mostra a existência de duas lógicas culturais distintas ao discorrer que a prática dos indígenas de receberem doações de não índios pode ser apreciada de formas diferentes segundo indígenas e não indígenas. Segundo a observação da autora, a prática - que pode ser vista como mendicância pelos não indígenas - é, sob a ótica dos indígenas, uma forma de habitar o mundo, "orientada pelos princípios da reciprocidade, da partilha de substâncias e pela lógica da circulação de bens, com base nos quais os laços de parentesco são produzidos e atualizados” (p. 171). Dentre as conclusões da autora, está a de que a apropriação do espaço urbano ("urbanidade") também é passível de atribuir outros sentidos e valores aos Mbyá. Ainda para ela, "está sempre presente o risco de que as políticas públicas voltadas para os povos indígenas propostas pelo Estado se construam com base na fantasia colonial a respeito do Outro" (p. 179) e, para a construção de políticas, fazse necessário "descontruir o estereótipo do índio genérico que vive em aldeias localizadas nas selvas de natureza intocada" (p. 180).

Jo Phelan, Bruce Link e John Dovidio, autores norte-americanos, finalizam a coletânea discutindo os conceitos de preconceito e estigma, "a partir dos autores que lhe deram vida” (p. 183) - Gordon Allport (A Natureza do Preconceito, de 1954) e Erving Goffman (Estigma: anotaçôes sobre o gerenciamento de uma identidade marcada, de 1963) -, mostrando que "desde então, teorias claramente distintas se desenvolveram em torno desses conceitos" (p. 183). Analisando literatura concernente, os autores parecem indicar que os estudos costumam tratar os dois termos sem grandes distinçôes conceituais: "concluímos que os modelos de preconceito e estigma definem um único animal” (p. 200), ainda que "os trabalhos na tradição do preconceito vieram de preocupações com 
processos sociais alimentados pela exploração e pela dominação, tais como o racismo, ao passo que na tradição do estigma se concentraram mais em processos fomentados pela imposição de normas e pela prevenção de doenças” (p. 200). Ao examinar os usos desses termos na literatura, os autores puderam delinear, no seu conjunto, uma tipologia de funções de estigma e preconceito, a saber: exploração/dominação; imposição de normas sociais; e prevenção de doenças.

Ao reunir autores com perspectivas teórico-disciplinares variadas, o intuito de Simone Monteiro e Wilza Villela de contribuir com o campo da Saúde Coletiva brasileira com o desenvolvimento de pesquisas e políticas voltadas para o entendimento do estigma e da discriminação associados à saúde foi alcançado com enorme êxito. Com base na integração de diferentes campos disciplinares, reconhecendo as conexões - e desconexôes - entre produção acadêmica da Saúde Coletiva e as práticas que correm nos serviços de saúde ou na gestão, as autoras sustentam que a compreensão entre condições de saúde, estigma e discriminação deve "ir além da descrição das experiências individuais e levar em contar os marcadores sociais da diferença que historicamente produzem desigualdades, como classe social, gênero, cor/raça, etnia, diversidade sexual, entre outros" (p. 17).

A leitura desse rico material nos sugere, portanto, vários sentidos do estigma para o estudo no âmbito da Saúde Coletiva: preconceito, discriminação, vulnerabilidade, violência simbólica, violência estrutural, sofrimento, dentre outros. A coletânea ainda nos brinda com sofisticados comentários de José Ricardo Ayres, Vera Paiva e Peter Fry, em seu prefácio, orelha e contracapa, respectivamente. E, como assinala Ayres, a publicação é muito bem-vinda por trazer à Saúde Coletiva uma discussão quase restrita a alguns campos disciplinares específicos. Além disso, o livro diz respeito a vários tipos de estigma: nas palavras de Peter Fry, “estigmatização e preconceito estabelecem hierarquias. Por meio do repúdio e da marginalização, produzem sentimentos de superioridade, de um lado, e sofrimento de toda ordem, de outro”.

Ao promover o diálogo entre cientistas sociais e das ciências humanas em saúde com epidemiólogos, a coletânea Estigma e Saúde torna-se referência não só obrigatória como prazerosa para docentes, discentes, formuladores de políticas, profissionais de saúde e ativistas de diversos movimentos sociais. 
${ }^{1}$ Ver PARKER, R. e AGGLETON, P. Estigma, Discriminação e Aids. Coleção ABIA, Cidadania e Direitos, n. 1. Rio de Janeiro, ABIA, 2001; PARKER, R. \& AGGLETON, P. HIV and Aids-related stigma and discrimination: a conceptual framework and implications for action. Social Science \& Medicine, v. 57, n. 1, p. 13-24, 2003.

${ }^{2}$ Parker faz uma breve digressão sobre os autores que lhe influenciaram na adoção desse conceito. Destaco aqui dois nomes que aparecem com maior relevo no texto: Johan Galtung, sociólogo norueguês pioneiro na definição do conceito, e Paul Farmer, sociólogo que destaca o papel da pobreza na construção da vulnerabilidade à doença (p. 33).

${ }^{3}$ NOGUEIRA, Oracy. Vozes de Campos do Jordão: experiências sociais e psíquicas do tuberculoso pulmonar no Estado de São Paulo. 2.ed. Rio de Janeiro: Fiocruz, 2009. 228 p. (Coleção História e Saúde; Clássicos e Fontes). 